\title{
Patent applications and neurotic concerns: further explorations in the Patent Office
}

\author{
David V. James and Paul L. Gilluley
}

It is a commonplace of clinical practice that those with obsessional disorder, or with obsessional features to a psychotic illness, often develop concerns about cleanliness and contamination. some with a focus on everyday bodily processes. In a search of the Patent Office for psychotic ideas (James \& Gilluley, 1997), it became apparent that patents reflecting concern about bodily functions were strongly represented in the patent collection. These stood out from patents concerning innovation in conventional medicine or medical appliances, and some of them had the flavour of the more bizarre ideas on the subject put forward by patients in our psychiatric practice. It was decided to explore the collection of the Patent Office further, with a view to surveying the range of such patents and examining their relation to the times in which they originated. The procedure used was the same as in our previous article.

\section{Findings}

A search of relevant categories found that two areas were greatly over-represented, these concerning sexual matters and excretion. This appears to have been the case across the century. These areas are critically surveyed below, with an emphasis on the typical rather than the grotesque.

Patents concerned with sex reflect the preoccupations of the time in which they were filed. In 1907, a patent for 'Sexual Armour', to protect the wearer against masturbation, stated: "It is a deplorable, but well-known fact that one of the most common causes of insanity. imbecility and feeble-mindedness, especially in youth, is due to masturbation. This is about equally true of both sexes." Similar sentiments were not uncommon in other patents of the day. By 1968, the emphasis had changed and a patent for a vibrator stated: "Experts in the field of medicine, especially of psychology, are unanimous in their views that, when sexual union between two persons of the opposite sex is unsatisfactory, they suffer from neurotical tensions which may develop into psychic diseases . . . (and are) one of the root causes of nervous and psychological ailments, including mental illness." The concern of 1968 is to facilitate orgasm, not prevent it, but the body armour survives, adapted to the concerns of the time. A USA patent from 1986 for a 'Protective Undergarment' describes a locked form of chain-mail underwear which protects against sexual attack, not being removable "without the use of tools not normally carried by persons intent upon a sexual attack".

An American patent from 1856 describes a 'Surgical Appliance'. The purpose of this invention, which involves surrounding the penis in a ring of spikes, and which was designed to be permanently securable to the wearer, was: "first. to prevent involuntary nocturnal seminal emissions; second, to control waking thoughts: and, third, to prevent self-abuse" (Fig. 1). The spikes reappear in a USA patent from 1994; but, this time, they are worn inside the vagina, and referred to as 'spears'. Comprising sharp elements of flexible plastic, these move only inward, and the sexual attacker finds himself securely and painfully trapped into the device. The spear concept is applied more literally in the Penis Locking and Lacerating Vaginal Insert', which originates in California. Similar in concept to the previous device, this one is a hollow tube inserted into the vagina with a rigid blade down its centre, upon which the unfortunate male impales himself. A kinder patent originates from the East Coast in 1985, in which the insert merely releases an adhesive and an irritating substance onto the penis.

Aids for the production of an erection or the enlargement of breast size appear common to the present and the late 19th century. Devices range from complex suction machinery with hundreds of parts to simple suction devices, one 'Breast Development Apparatus' from 1975 appearing curiously similar to a plumber's suction plunger (Fig. 2). There is a 1991 patent for a method of fixing a dildo permanently to a piece of furniture, and a selection of unlikely 

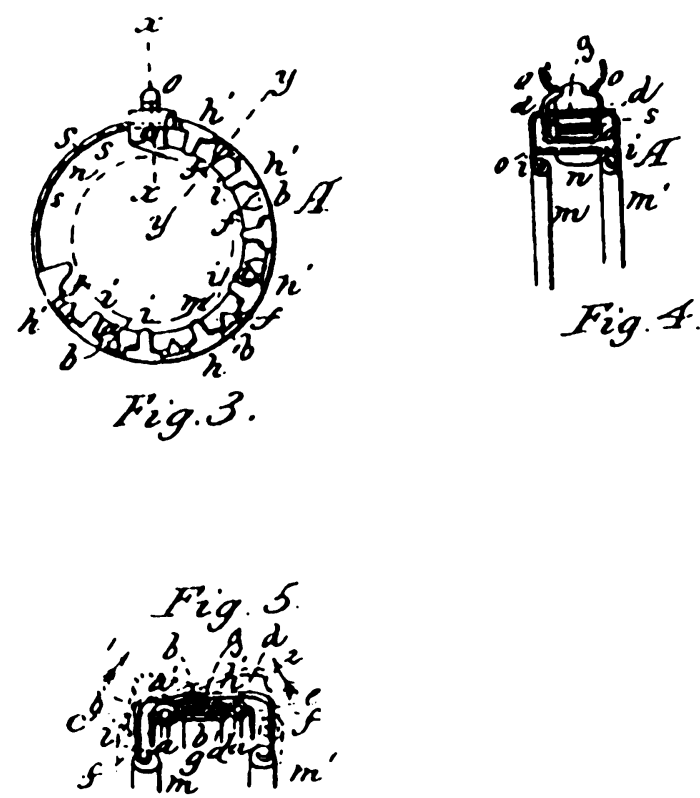

Figure 1. Device for the prevention of nocturnal emissions.

articles of furniture to aid intercourse, some of them suspended from the ceiling. Since the advent of HIV, much creative attention has been given to methods of engaging in intercourse with the lowest possible risk. Condoms can be found as incorporated into ear-rings, cigarette lighters, toothbrushes and in a special box, which needs dual-key opening, one key being held by each

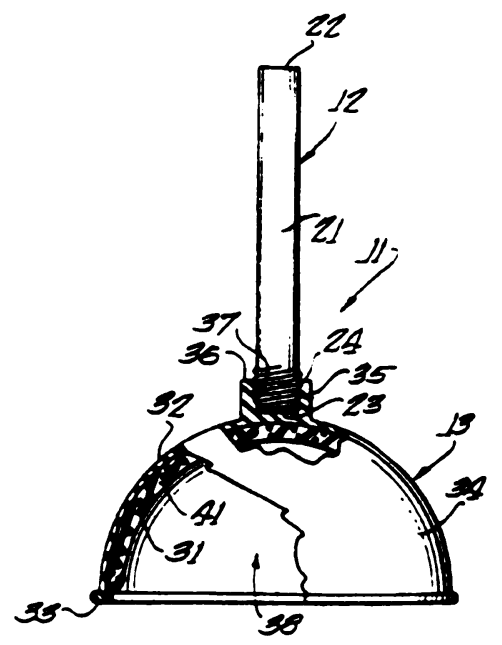

Figure 2. Breast development apparatus. partner "to ensure mutual consent". Condoms can be warmed as part of a "Combined Radio and Condom-Warming Device' (Fig. 3). There is a 'Force-Sensitive. Sound-Playing Condom' for the musically inclined, which will not be further described here. Those worried about the mechanics of condom application may avall themselves of a 1991 'Orientation-Indicating Condom', which has a palpable design on one side. An alternative is the no-hands approach with a 1990 'No Hands Contraceptive Device' (a condom), the description for the operation of which is unconvincing.

For those concerned about oral or oro-genital HIV transmission, a number of facial guards have been patented, covering most of the face, but with an in-built protuberance to admit a tongue or other body part. And if a simple condom does not seem enough, several designs for contraceptive underwear are available, giving total protection below the waist. A 1989 French patent for 'Anti-Aids Underpants' has an elongated protuberance for 'protecting and isolating the male sexual organ from that of his female or male partner'. An American patent from the following year goes one better, having several tubular extensions, which can be inverted for wear by the female and allow access to more than one orifice (Fig. 4). An alternative, or perhaps complementary approach for the very wary, is the 'Microbicidal Cleanser/Barrier Kit'. which allows the potential user a means of cleansing himself by extensive application of a povidone-iodine mixture three hours before intercourse and once again shortly thereafter. As for the climax of all this sexual activity, it should be noted that several patents already exist for the word 'orgasm', specifically when

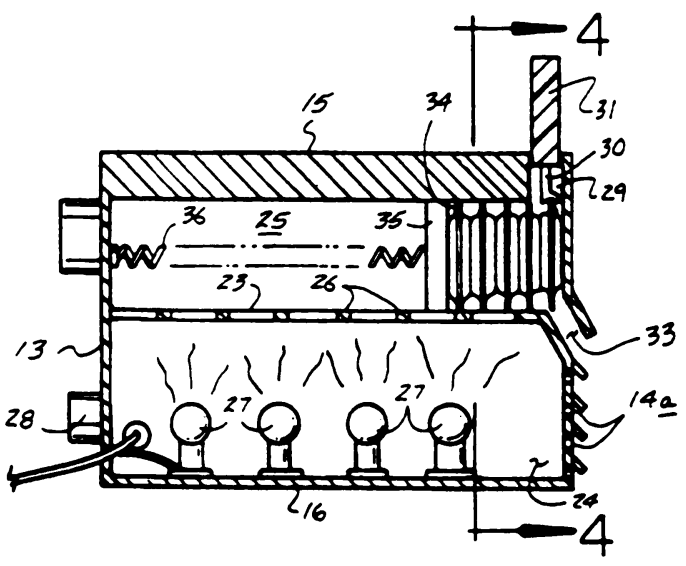

Figure 3. Combination condom warming and radio apparatus. 


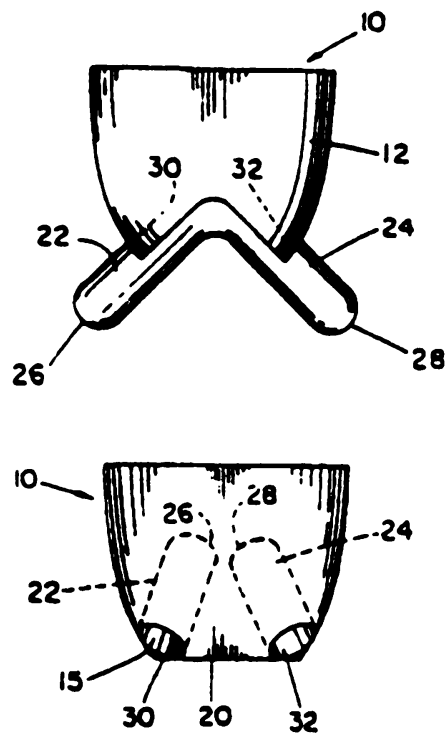

Figure 4. Unisex condom underpants.

used in combination with the word 'chocolate' and when used in connection with any form of make-up or toiletry.

Many of the patents concerning excretory function detail devices which go well beyond the realm of surgical appliance catalogues. Again, patents reflect the concerns of their time. A 1902 patent for Improvements in Chamber Utensils and Attachments Therefore' details a design of chamber pot which may be used noiselessly. It contains "special interior surfaces adapted to receive the impact of fluid and avoid the striking of fluid upon fluid, which is what causes the objectionable sound". A UK patent from 1988 reverses the principle, being a sensor device for toilet bowls and urinals which can be set up to arrange a sound or music to play when activated. A patent from 1903 on 'Improvements in Urinals for the Use of Females' is a piping contraption for allowing females to urinate standing up. The purpose is stated as being to avoid "the inconvenience of the necessity of raising the dress to the level of the closet seat". Two US patents from 1989 and 1990 achieve the same positional aim by means of an insertional device. Their purpose is unclear, but must be different from that of 1903 , given that their use would inevitably involve disturbance of the clothing. The matter is confused further by the patenting in recent years of a number of public education signs, instructing men to urinate in a sitting rather than a standing position. Delicacy about the subject is still evident. A 1993 patent describes a raincoat equipped with interior arm-holes and a collection device for secret urination. the sleeves cleverly being equipped with lowerable simulated hands to preserve the deception. A 1988 patent originating in Japan describes an alarm device for informing a man that his trouser zip is undone, thus preventing "the occurrence of embarrassment, injury, loss or damage". A 1939 device, described as a "gas receptor', concerns a rigid pipe inserted into the rectum and attached to a collection bag. A more modern American device along similar lines from 1980 is the Toilet Seat Volatile Gas Incinerator', which involves a suction mechanism in the toilet bowl and the passing of the air therefrom over a heated tungsten flament, so destroying "odorous volatile body gases". Neurotic concerns have gone high-tech.

\section{Comment}

This examination of patents from the past 100 years indicates that the Patent Office is a repository of information about social attitudes to bodily functions, and that its contents reflect changes in what was considered acceptable, as the century progressed. At each stage, a number of different approaches to the matter are in evidence. Principal among these are inventions which reflect extremes of neurotic concern about bodily function, and inventions which seek to exploit the over-concern of the susceptible or impressionable. Contemporary medical opinion as to what is healthy for mind or body can be seen to underlie, albeit at some distance, the reasoning behind some of the inventive zeal. Concerns about sex have developed from its avoidance, to more liberated attitudes, through to modern-day preoccupation with sexually transmitted disease and sexual violence. Some of the patented designs of physical contraptions suggest that matters have come full circle. Concerns about excretory function have varied less, other than with technology. but have perhaps produced more unusual ideas and cultural variation.

The patents are almost exclusively the products of individuals, rather than companies. They share in common specific and, to the average person, exaggerated concern about elements of everyday bodily function. The individual inventions are based on simple premises. It is unlikely that many of them would work and, apart from a few of the more exploitative novelty items, it is improbable that they have ever been put into production, or indeed, tested in the field. It is this which sets them apart from mainstream inventions or developments and which suggests that a significant minority of inventions and devices in the patent library constitute an expression of 
neurotic symptomatology or obsessional preoccupation, the specific content of which is coloured by the concerns of the times.

\section{Reference}

JAMES, D. V. \& GILULEY, P. L. (1997) Psychotic patients and patent applications. The mad scientist revisited? Psychiatric Bulletin, 21, 764-768.
*David V. James, Consultant Forensic Psychiatrist, Camlet Lodge RSU, Chase Farm Hospital Campus, The Ridgeway, Enfield, Middlesex EN2 8J; and Paul L. Gilluley, Registrar in Forensic Psychiatry, Henry Rollin Unit, Long Grove Road, Epsom, Surrey KT19 8PZ

*Correspondence 